\title{
PHENOMENA INTRUSI DASAR DI TELUK HURUN LAMPUNG
}

\author{
Oleh : \\ Arif Dwi Santoso \\ Peneliti di Pusat Teknologi Lingkungan, Kedeputian TPSA, BPPT
}

\begin{abstract}
Research aimed to learn and know the bottom intrusion mechanism in Hurun Bay Lampung. Three kinds surveys were conducted consist of mooring survey, synoptic oceanographic survey and 25 hour survey. The monitoring data of water temperature indicated that at Hurun Bay occurred bottom intrusion from middle February until early July. The mass water was colder, more saline and contained less DO than the overlaying water. These phenomena may be caused by eastern monsoon from Java Sea to Lampung Bay and Hurun Bay. Vertical profile distribution showed that there are significant different in temperature, salinity and DO between surface and bottom layer. Along bottom deeper than $22 \mathrm{~m}$ were identified as a termocline layer which was colder and more saline and contained less DO. Result of 25 hour survey resumed that the lowest DO in this water mass appeared in early July and it propagated from offshore to the coast with velocity $0.07 \mathrm{~m} / \mathrm{s}$. This condition will be a treatment for marine cultivation stakeholder in this area.
\end{abstract}

Key words : Bottom Intrusion, Hypoxia

\section{PENDAHULUAN}

Kegiatan budidaya perikanan laut dalam keramba jaring apung (KJA) di Indonesia telah berkembang sejak tahun 1990 (Ahmad, T, 1990). Dalam perjalanannya perkembangan kegiatan budidaya tersebut mengalami pasang surut karena berbagai kendala yang belum terpecahkan. Di samping kendala operasional seperti masalah benih, penyakit, pakan, dan pemasaran, kendala pendukung seperti iklim/cuaca, dinamika pantai juga sering menjadi masalah bagi kegiatan budidaya perikanan di Indonesia. Salah satu dinamika pantai yang perlu mendapat perhatian adalah adanya pergerakan massa air di dasar perairan yang berkadar oksigen terlarut rendah yang berpotensial menyebabkan Hypoxia.

Hypoxia adalah suatu kondisi perairan dimana kandungan oksigen terlarutnya berada pada kisaran dibawah nilai ambang kebutuhan kebanyakan biota di perairan (Rabalais et al, 2001). Fenomena ini akan memicu beberapa masalah lingkungan seperti kejadian kematian massal ikan di areal budidaya ikan dalam keramba jarring apung (KJA). Di beberapa negara sub tropis seperti Jepang, hypoxia sering terjadi di daerah dasar pantai pada musim panas. Proses terbentuknya hypoxia terjadi karena adanya perbedaan stratifikasi air yang besar yang menyebabkan penurunan oksigen transport secara vertikal (Hayami, et al., 2005). Akibatnya oksigen terlarut di dasar perairan menjadi berkurang, bila hal ini berlanjut kondisi dasar bisa menjadi anoxic (Pawar V., et al, 2001).
Di perairan tropis, kondisi stratifikasi perairan seasonal relatif kecil akibat dari intensitas penyinaran matahari yang berlangsung terus menerus sepanjang tahun. Sehingga kemungkinan terjadinya fenomena hypoxia di perairan tropis adalah kecil (Pariwono, 1998). Namun demikian kita menemukan kasus kejadian intrusi dasar yang menyebabkan hypoxia di areal budidaya ikan KJA di Teluk Hurun Lampung. Dalam tulisan ini kami mencoba untuk mengungkap dan menerangkan proses terjadinya intrusi dasar yang menyebabkan hypoxia di Teluk Hurun Lampung.

\section{BAHAN DAN METODE}

Lokasi penelitian ini berada di Teluk Hurun Lampung. Teluk ini berada di arah timur laut dari Teluk Lampung pada koordinat sekitar $5^{\circ} 31.5^{\prime} \mathrm{S}$ dan $105^{\circ} 15^{\prime} E$ (Gambar 1). Adapun gambaran umum dari Teluk Hurun adalah sebagai berikut : kondisi muara teluk di bagian utara (dekat stasiun1) terdapat mulut sungai yang membawa limpasan air dari pemukiman penduduk dan lahan pertanian. Areal ini masih diselimuti hutan mangrove yang lebat, sementara di bagian selatan di sekitar stasiun 2 dan 4 terdapat beberapa petak tambak tradisional yang saluran pembuangannya langsung menuju ke pantai. Di sekitar mooring B (stasiun 5) terdapat 3 unit KJA yang dioperasikan oleh Balai Budidaya Laut (BBL) sementara di lepas pantai (mooring C) terdapat kegiatan budidaya kerang mutiara. Kedalaman rata-rata teluk sekitar $15 \mathrm{~m}$. 


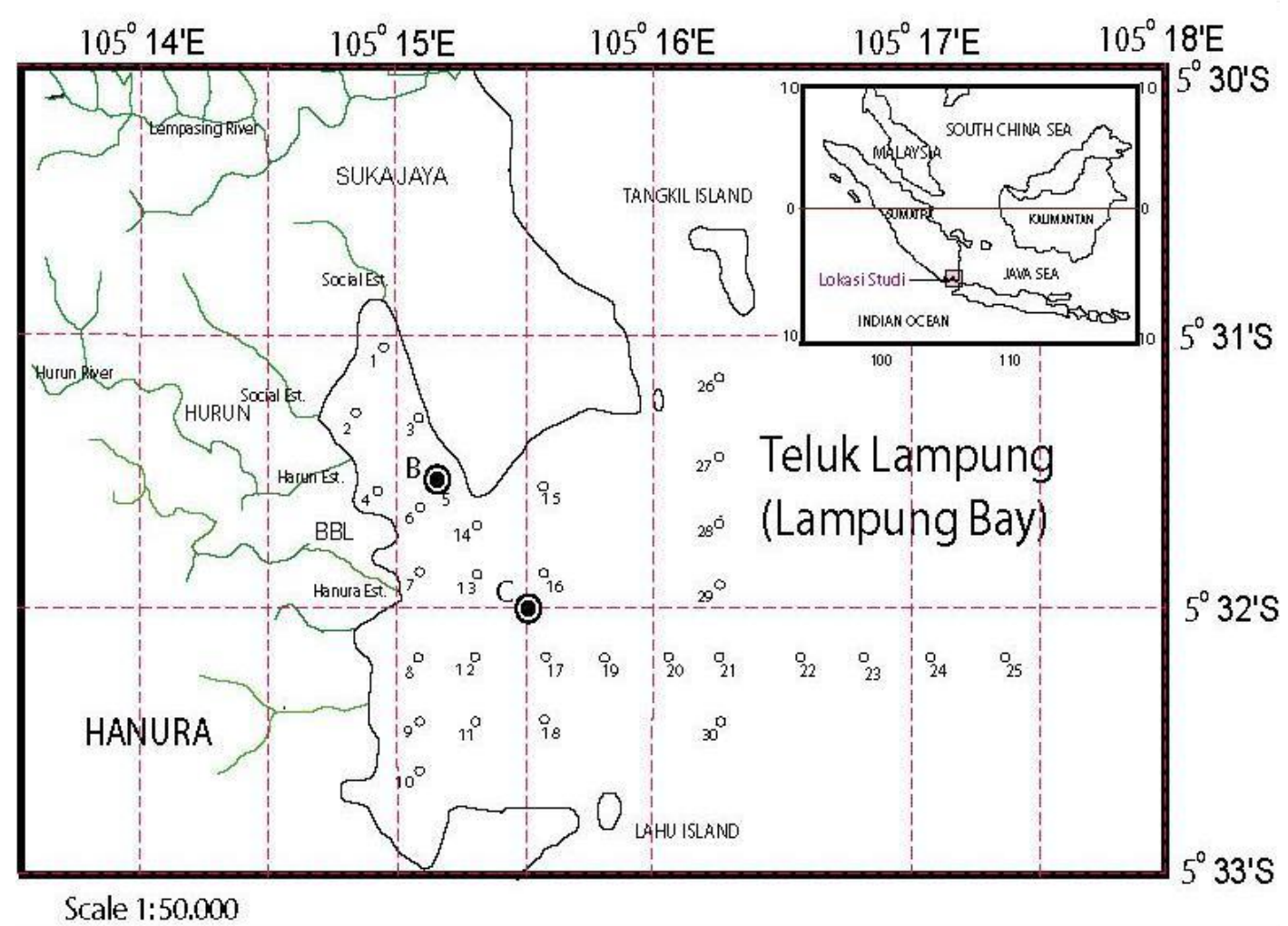

Gambar 1 : Peta Teluk Lampung dan posisi stasiun-stasiun pengambilan sampel

Survey pertama yakni survey mooring dilakukan dengan menempatkan 16 sensor suhu (HOBO Water Temp Pro, onset computer) pada stasiun mooring B sebanyak 6 sensor dan stasiun C sebanyak 11 sensor. sensor-sensor tersebut disusun secara vertikal dengan interval $2 \mathrm{~m}$ dari permukaan hingga dasar perairan.

Survey kedua adalah survey synoptic oceanographic yang dilakukan dua periode yakni tanggal 5-7 Februari dan tanggal 17-19 Juli 2003. Dalam survey ini dilakukan pengambilan data dengan chlorotec probe (Chlorotec, type AAQ1183, Alec Electronics) sebanyak 30 stasiun dan pengambilan sample air untuk analisis kimia sebanyak 10 stasiun. Data yang bisa diambil dari chlorotec probe meliputi data suhu air, salinitas, DO, turbiditas, $\mathrm{PH}$ dan $\mathrm{d}$ chlorophyll a. Sementara nutrient yang dianalisa meliputi nitrit, nitrat, fosfat dan silikat.

Survey ketiga adalah survey 25 jam. Survey ini dilakukan untuk mengetahui dinamika kandungan oksigen yang disebabkan oleh kegiatan respirasi oleh badan air. Survey ini terdiri dari pengambilan data dengan chlorotec probe setiap satu jam sekali dan pengukuran nutrient untuk analisa kimia. Pengambilan sample air dilakukan pada kedalaman $0 \mathrm{~m}, 5 \mathrm{~m}$ and $10 \mathrm{~m}$.

\section{HASIL DAN BAHASAN}

Data hasil observasi mooring sensor temperatur menunjukkan terjadinya intrusi dasar yang membawa oksigen terlarut rendah dan suhu sekitar $29.3^{\circ} \mathrm{C}-29.5^{\circ} \mathrm{C}$ (rata-rata 29.4) pada pertengahan bulan Februari hingga awal bulan Juli 2003. Sedangkan suhu tertinggi tercatat pada pertengahan bulan April hingga awal bulam Mei 2003 dengan kisaran $31.1^{\circ} \mathrm{C}-31.5^{\circ} \mathrm{C}$ (rata-rata $31.3^{\circ} \mathrm{C}$ ) (Gambar 2). Observasi data mooring juga menunjukkan adanya penurunan suhu air sekitar $1.5^{\circ} \mathrm{C}$ pada dasar perairan pada awal bulan Juli 2003. Untuk mengetahui arah dan kecepatan massa air yang bersuhu rendah ini, kita membandingkan data suhu dasar perairan antara stasiun B dan stasiun C. Massa air bersuhu rendah tersebut bergerak menuju ke pantai dengan kecepatan $0.07 \mathrm{~m} /$ det (Gambar 3). Data mooring temperature juga menunjukan intrusi dasar perairan yang membawa massa air yang berkadar oksigen terlarut rendah dan bertemperatur rendah. Intrusi dasar tersebut merupakan efek dari hembusan Angin Muson Tenggara yang berpotensial menyebabkan upwelling. Proses mekanisme pembentukan intrusi dasar dimulai dari upwelling yang terjadi di laut Jawa, kemudian upwelling bergerak ke Tenggara Jawa dan perairan Sumatra dan akhirnya mencapai Teluk Lampung pada awal Juli. Menurut Susanto, 2001 terjadinya upwelling di sepanjang pantai Jawa-Sumatra merupakan respon terhadap bertiupnya angin Muson Tenggara. Upwelling pada daerah ini berlangsung pada bulan Juni hingga pertengahan Oktober. 


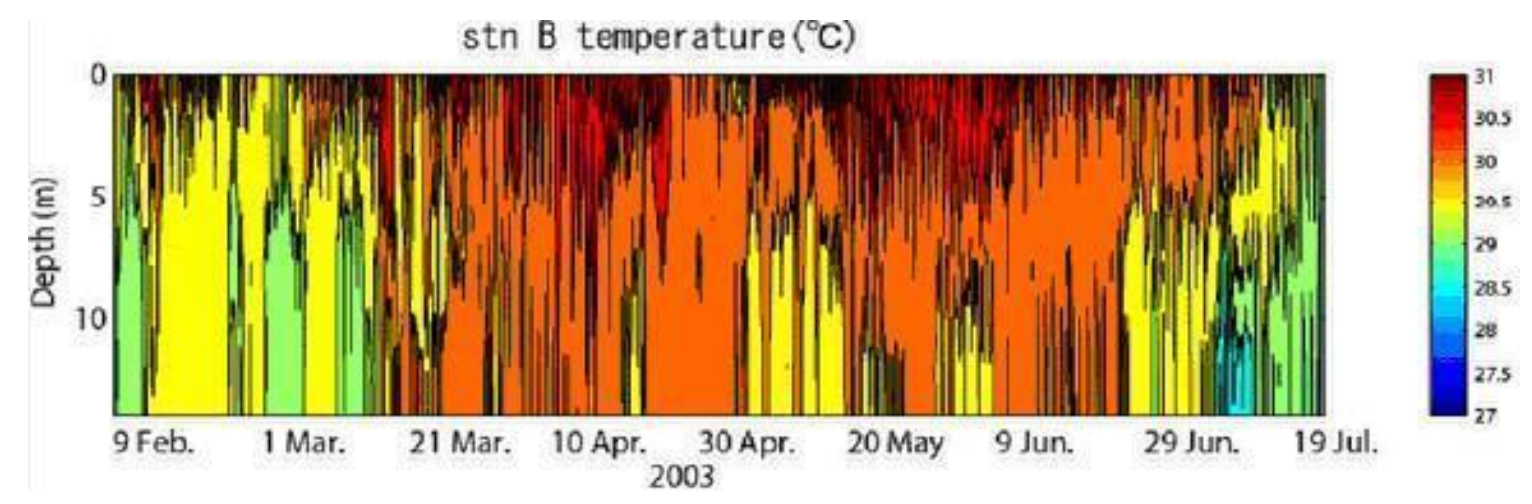

Gambar 2. Data time series temperatur pada stasiun B.

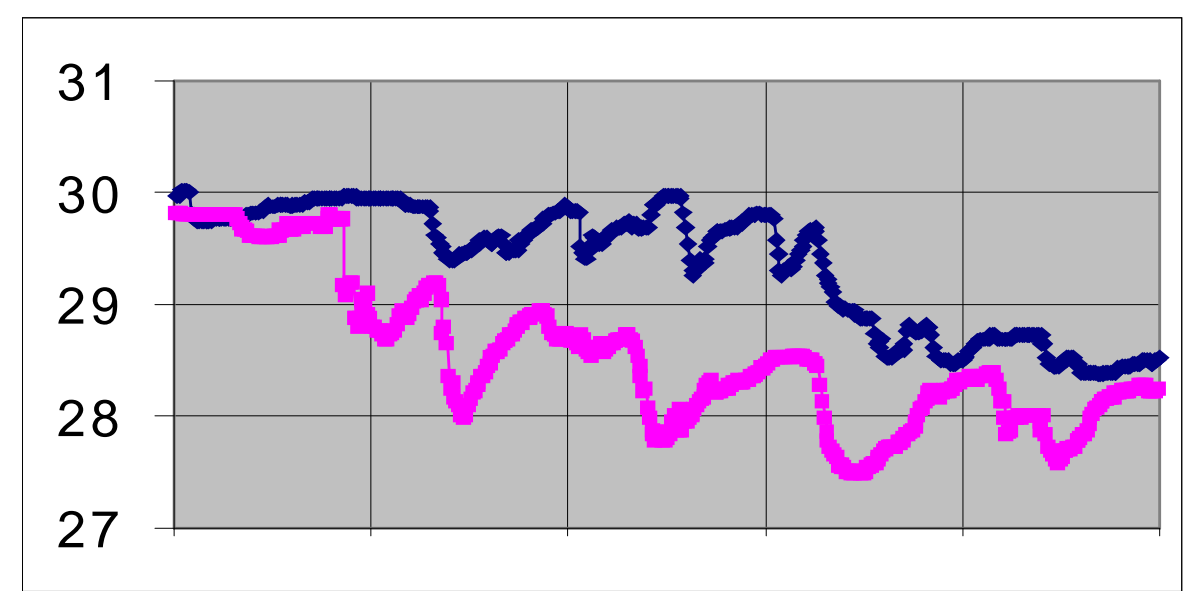

Gambar 3 : Temperatur dasar perairan pada tanggal 2-6 Juli pada stasiun B dan stasiun C.

Fenomena terjadinya intrusi dasar perairan di Teluk Hurun Lampung yang membawa masa air yang berkonsentrasi oksigen rendah, salinitas tinggi dan temperatur rendah terlihat jelas dari grafik distribusi vertikal dan sebaran DO dasar perairan di setiap stasiun pengamatan. Grafik distribusi vertikal dari temperature, salinitas dan oksigen terlarut pada stasiun 30 ditampilkan pada gambar 5. Dalam grafik tersebut terlihat jelas perbedaan yang drastis dari konsentrasi oksigen

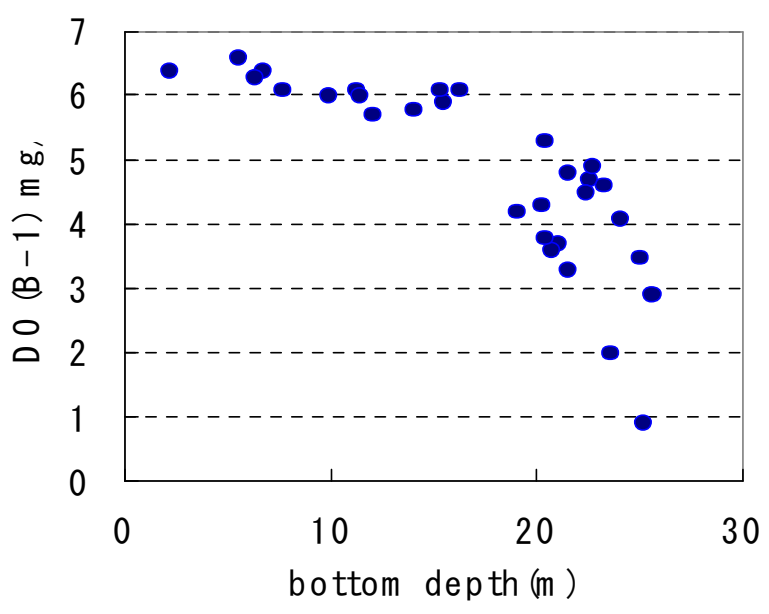

Gambar 4 : Kondisi oksigen terlarut $1 \mathrm{~m}$ di atas dasar pada seluruh stasiun. terlarut antara permukaan dan dasar perairan. Pada dasar perairan konsentrasi oksigen terlarut lebih rendah dari $1 \mathrm{mg} / \mathrm{L}$. Di lokasi tersebut dapat diindikasi terjadi lapisan thermocline pada kedalaman sekitar $22 \mathrm{~m}$. Gambar 4 menunjukan konsentrasi oksigen terlarut pada kedalaman $1 \mathrm{~m}$ di atas dasar perairan. Data tersebut memperlihatkan bahwa konsentrasi rendah oksigen terlarut hampir tersebar di seluruh kedalaman $20 \mathrm{~m}$.

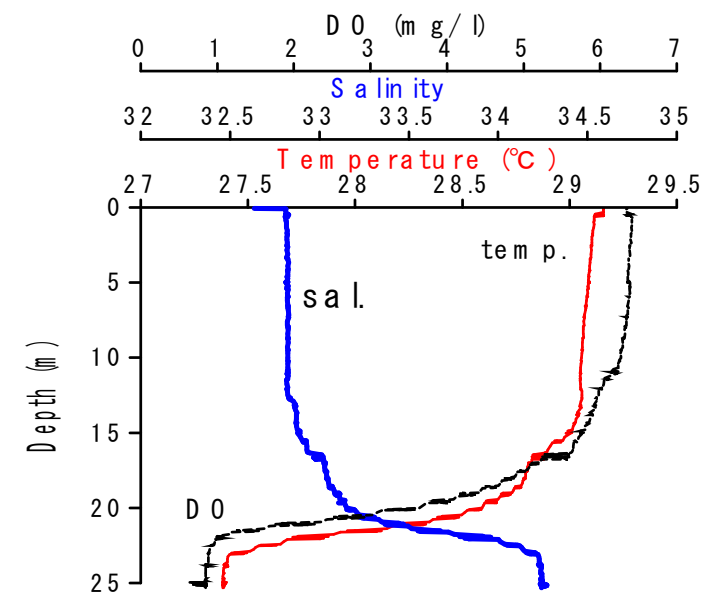

Gambar 5 : Distribusi vertikal dari temperatur, salinitas dan oksigen terlarut pada stasiun 30 . 


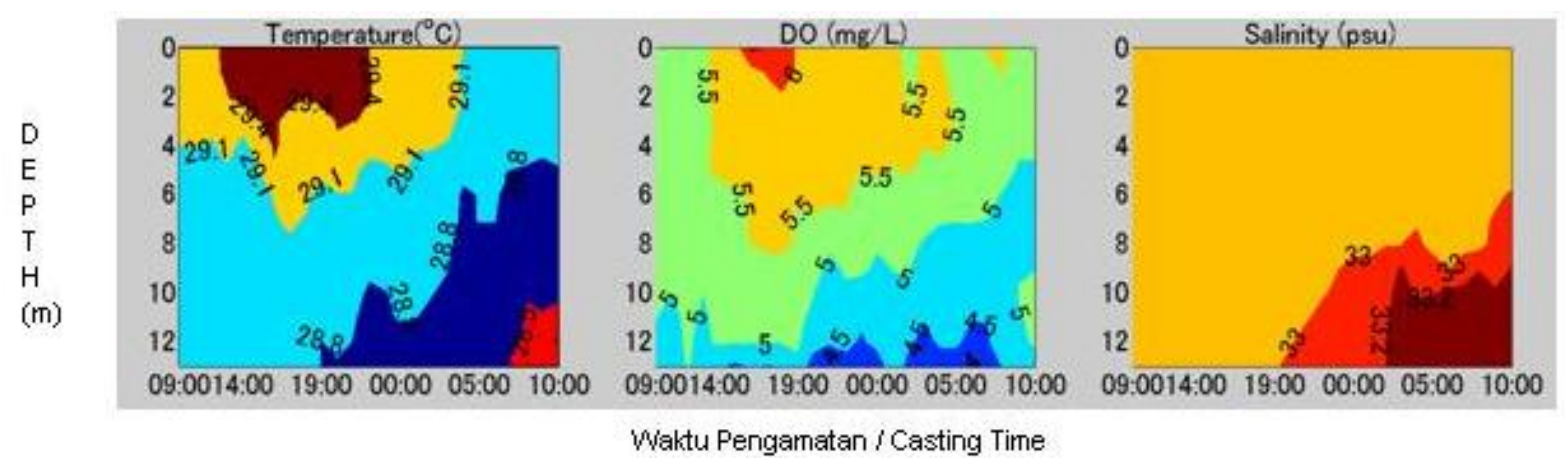

Gambar 6 : Profil Vertikal Temperatur, DO dan Salinitas pada stasiun 5 selama 25 jam survey.

Intrusi dasar perairan ternyata juga merambah hingga ke perairan pantai Teluk Hurun. Data hasil survey 25 di stasiun 5/B menguatkan dugaan hasil survey sebelumnya. Massa air dengan konsentrasi oksigen rendah, salinitas tinggi dan temperatur rendah ditemukan di perairan pantai pada kedalam sekitar $20 \mathrm{~m}$ (Gambar 6).

\section{KESIMPULAN}

Fenomena intrusi dasar perairan yang menyebabkan Hypoxia ditemukan di Teluk Hurun pada awal bulan Juli 2003. Fenomena ini ditimbulkan oleh pengaruh angin Muson Tenggara yang membawa massa air berkadar oksigen terlarut rendah, salinitas tinggi dan temperatur rendah dari Laut Jawa ke Teluk Lampung hingga masuk ke Teluk Hurun. Intrusi dasar perairan tidak hanya terjadi di lepas pantai tapi merambah sampai ke daerah pantai. Kondisi seperti ini jelas menjadi ancaman bagi pengelola budidaya perikanan di areal tersebut karena, pertama : di daerah pantai massa air di pantai mempunyai statifikasi temperatur yang rendah dan mudah teraduk oleh arus atau angin sehingga badan air semakin badan air akan mudah menjadi anoxic. Kedua: dari hasil survey $25 \mathrm{Jam}$, di daerah pantai (KJA) mempunyai produktifitas tinggi sehingga sangat rentan bila terjadi massa air yang hypoxic (kekurangan oksigen).

Mencermati kemungkinan terjadinya Hypoxia di Teluk Hurun yang sarat dengan kegiatan budidaya laut seperti KJA, disarankan untuk menghindari penebaran benih ikan atau specimen benih karang mutiara pada bulan Juni - Juli. Benih ikan atau aktifitas penebaran awal biasanya sangat rentan terhadap perubahan lingkungan yang ekstrim. Hal lain yang perlu mendapat perhatian adalah upaya peningkatan kualitas operasional kegiatan budidaya, misalnya penentuan stocking rate yang tepat, pengetahuan tentang feeding habit yang baik dan selalu menjaga kebersihan lingkungan lokasi budidaya.

\section{DAFTAR PUSTAKA}

1. Ahmad, T (1990) Status and prospect of marine aquaculture in Indonesia. IARD Journal, 12(3): 47-53.

2. Dwi Susanto R., A. L. Gordon and Q. Zheng (2001) Upwelling along the coasts of Java and Sumatra and its relation to ENSO. Geophysical Research Letters 28: 15991602.

3. Hayami, Y., Koji Omori, Arif Dwi Santoso, Agung Riyadi, Muawanah, and Hidetaka Takeoka, (2005). Hypoxic water mass in Lampung Bay, Indonesia. International workshop on coastal water environment in Lampung Bay, Jakarta, June 8. 2005. 5pp.

4. Pariwono, J.I. (1998) Kondisi Oseanografi perairan pesisir Lampung. Proyek pesisir publication, Techical Report (TE-99/12-I) Coastal Research Center, University of Rhode Island, Jakarta, Indonesia, 24pp. (In Indonesian)

5. Pawar, V., Matsuda, O., Yamamoto, T., Hashimoto, T., Rajendran, N. (2001) Spatial and temporal variations of sediment quality in and around fish cage farms: A case study of aquaculture in the Seto Inland Sea, Japan. Fisheries Science. 67:619-627.

6. Rabalais, N. and E. Turner Ed.(2001) Coastal Hypoxia-consequences for living resources and ecosystems-American Geophysical Union. 463pp. 